\title{
Early detection of global and regional left ventricular diastolic dysfunction in systemic lupus erythematosus: the role of the echocardiography
}

Ana Claudia Soares Teixeira ${ }^{1}$, Eloisa Bonfá ${ }^{2}$, Nathan Herskowictz ${ }^{3}$, Alfonso Júlio Guedes Barbato ${ }^{4}$, Eduardo Ferreira Borba ${ }^{5}$

\begin{abstract}
Introduction: Bidimensional echocardiography is a non-invasive imaging diagnostic method that effectively assesses global and regional left ventricular diastolic function. Disruption of left ventricular diastolic function in systemic lupus erythematosus (SLE) is almost always clinically silent, suggesting a subclinical diastolic dysfunction. Objective: We evaluate in the the present study the different echocardiographic techniques available to assess the diastolic dysfunction in SLE. Patients and Methods: Fifty consecutive SLE patients and 50 healthy females, matched by gender and age, were evaluated. Exams were conducted by two independent observers whose results showed concordance. Results: Significant differences in global left ventricular diastolic function between both groups, except for mitral flow propagation velocity $(\mathrm{Vp})$, which showed a reduction in rapid filling in SLE patients, were not observed. Greater involvement of regional diastolic function, in protodiastole, at the level of the mitral ring, especially in the basal area of the interventricular septum, was observed. Conclusion: Left ventricular diastolic dysfunction in SLE patients can be identified by tissue Doppler of the mitral ring and by mitral flow propagation velocity.
\end{abstract}

Keywords: systemic lupus erythematosus, echocardiography, Doppler, diastolic function, ventricle.

\section{INTRODUCTION}

Echocardiography, whose assessment techniques have improved to provide more information on cardiac function, is a useful tool in cardiology. ${ }^{1}$

Currently, pulsed Doppler, a non-invasive technique, is extremely useful in the evaluation of global left ventricular (LV) diastolic filling. ${ }^{2}$ Several studies have confirmed the relationship between global LV relaxation abnormalities and specific patterns of transmitral flow velocity on pulsed Doppler. $^{3,4}$ Tissue Doppler (TD) is a variation of color Doppler that determines contraction and relaxation velocities of the myocardium, ${ }^{1}$ being a sensitive method of evaluating regional LV performance. ${ }^{5}$

Mitral flow propagation velocity (Vp) is another method recently incorporated into the evaluation of LV diastolic function, since it determines blood velocity in a single area of the cardiac chamber. Mitral flow propagation velocity $>55 \mathrm{~cm} / \mathrm{s}$ is normal in children, and in adults $>45 \mathrm{~cm} / \mathrm{s}$ is considered normal $^{6}$, since it is inversely related with increasing age. ${ }^{7}$

The incidence of valvular involvement on SLE is around $18 \%$, on transthoracic echocardiography, and $74 \%$ on transesophageal echocardiogram, ${ }^{8}$ which includes reports ranging from valvular thickening to severe cardiac dysfunction. ${ }^{8-18}$ In a Brazi-

Received on 06/29/2009. Approved on 11/22/2009. We declare no conflict of interest.

Radiology Department and Rheumatology Service of the Medical School of USP

Grants: National Council for Scientific and Technological Development (\#305468/2006-5, for EB, and \#303165/2008-1, for EFB) and Federico Foundation (for $\mathrm{EB}$ and $\mathrm{EFB}$ ).

1. Physician of the Rheumatology Department of the Medical School of Universidade de São Paulo (USP)

2. Full Professor of Rheumatology of the Medical School of USP

3. Physician of the Radiology Department of the Medical School of USP

4. Full Professor of the Radiology Department of the Medical School of USP

5. Associate Professor of Rheumatology of the Medical School of USP

Correspondence to: Dr. Eduardo F. Borba. Faculdade de Medicina da Universidade de São Paulo - Disciplina de Reumatologia. Av. Dr. Arnaldo 455, $3^{0}$ andar, Sala 3190, São Paulo - SP - Brazil. CEP: 01246-903. FAX: 55-11-30617490. E-mail: eborba@lim17.fm.usp.br 
lian study with 70 SLE patients, $11.4 \%$ presented mild systolic dysfunction; moderate in $7.1 \%$; and severe in $2.9 \%{ }^{16}$ On the other hand, a study with transesophageal echocardiography in SLE patients demonstrated preserved systolic function in the absence of left ventricular hypertrophy and arterial hypertension. ${ }^{17}$ Thus, it is believed left ventricular systolic involvement can be associated, mainly, to long-standing hypertension. ${ }^{18}$

Regional diastolic function in SLE has not been evaluated properly in prior studies, and it has been demonstrated that this dysfunction precedes the deterioration of left ventricular systolic function. Therefore, the objective of the present study was to assess global and regional left ventricular diastolic function in SLE patients when compared to healthy individuals using appropriate non-invasive methods with diagnostic accuracy.

\section{PATIENTS AND METHODS}

Fifty consecutive females with SLE followed at the Lupus outpatient clinic of the Rheumatology Department of Hospital das Clínicas of FMUSP from January 2004 to January 2005 were included in this study. Patients were younger than 35 years and fulfilled the SLE classification criteria of the American College of Rheumatology. ${ }^{19}$ The Systemic Lupus Erythematosus Disease Activity Index (SLEDAI) ${ }^{20}$ was used to evaluate disease activity. Exclusion criteria were as follows: hypertension, cardiopathies, history of smoking, and active disease (SLEDAI $\geq 6$ ). The control group was composed of 50 healthy females younger than 35 years who did not present any of the exclusion criteria. This study was approved by the Ethics on Research Committee of the Hospital das Clínicas of FMUSP (Registration 919/04) and all individuals signed an informed consent.

As per the study protocol, all patients underwent detailed history and physical exam, as well as blood pressure, heart rate, weight, and height at the day of echodoppler assessment.

\section{Echocardiographic assessment}

A General Electric Vivid 7 (Milwaukee, Wisconsin) with tissue Doppler, harmonic imaging, and ECG-synchronized image capture was used for all exams according to the echocardiographic techniques recommended by the Echocardiography Department of the Brazilian Society of Cardiology ${ }^{21}$ and the American Society of Echocardiography. ${ }^{22}$

M-mode, color M-mode, and bidimensional imaging, as well as color flow mapping and tissue Doppler (TD) were obtained by using a 2.5-MHz electronic transducer. M-mode of the Aorta (Ao) and left atrium (AE) was recorded at the level of the large thoracic vessels; left ventricular (LV) systolic and diastolic diameters, systolic and diastolic septum thickness, the posterior wall of the left ventricle, and the right ventricle were recorded at the level of the papillary muscles. Doppler volume sampler was placed parallel to the mitral valve flow to analyze ventricular filling velocity (E wave, $\mathrm{A}$ wave, and $\mathrm{E} / \mathrm{A}$ ratio).

Color M-mode recorded the regional velocities of ventricular filling: E' wave, A' wave, E'/A' ration, and mitral flow propagation velocity. Doppler volume sampler, which is also used to calculate LV performance index or TEI index, was positioned in the apical five-chamber approach to analyze ejection velocity.

\section{Tissue Doppler}

Tissue Doppler (TD) was obtained by the apical four-chamber approach and the volume sampler $(2-5 \mathrm{~mm})$ was positioned at the level of the mitral ring, on the lateral and septal walls. Tissue Doppler was placed on pulsatile Doppler mode and filters were programmed to exclude high frequency signs while the Nyquist limits were adjusted for velocities of 15 to $20 \mathrm{~cm} / \mathrm{s}$. The volume sampler was positioned on the left ventricular myocardium, adjacent to the mitral ring, obtaining graphic TD curves of the lateral and septal portions of the mitral ring (Figure 1A).

\section{Estimated left atrial pressure (LAP)}

Doppler volume sampler was positioned on the extremities of the mitral valve leaflets for acquisition of the maximal velocity of the E wave. Afterwards, maximal E' wave velocity was measured using the TD mode at the level of the lateral portion of the mitral ring. The following equation was used:23

$$
\mathrm{LAP}(\mathrm{mmHg})=1.24 \times\left(\mathrm{E} / \mathrm{E}^{\prime}\right)+1.9
$$

\section{Color M-mode}

To determine the mitral flow propagation velocity, the transducer was aligned with the LA, mitral valve, and LV. A space-temporal map of the blood velocities expressed by different colors, in which flows towards the transducer are represented by shades of yellow/red, and those going away from the probe are represented by different shades of blue, is obtained (Figure 1B).

Initial mitral flow propagation velocity $(\mathrm{Vp})$ is not affected by the dimension or blood volume, but it is affected by disrupted left ventricular function. ${ }^{24}$ Mitral flow propagation velocity 


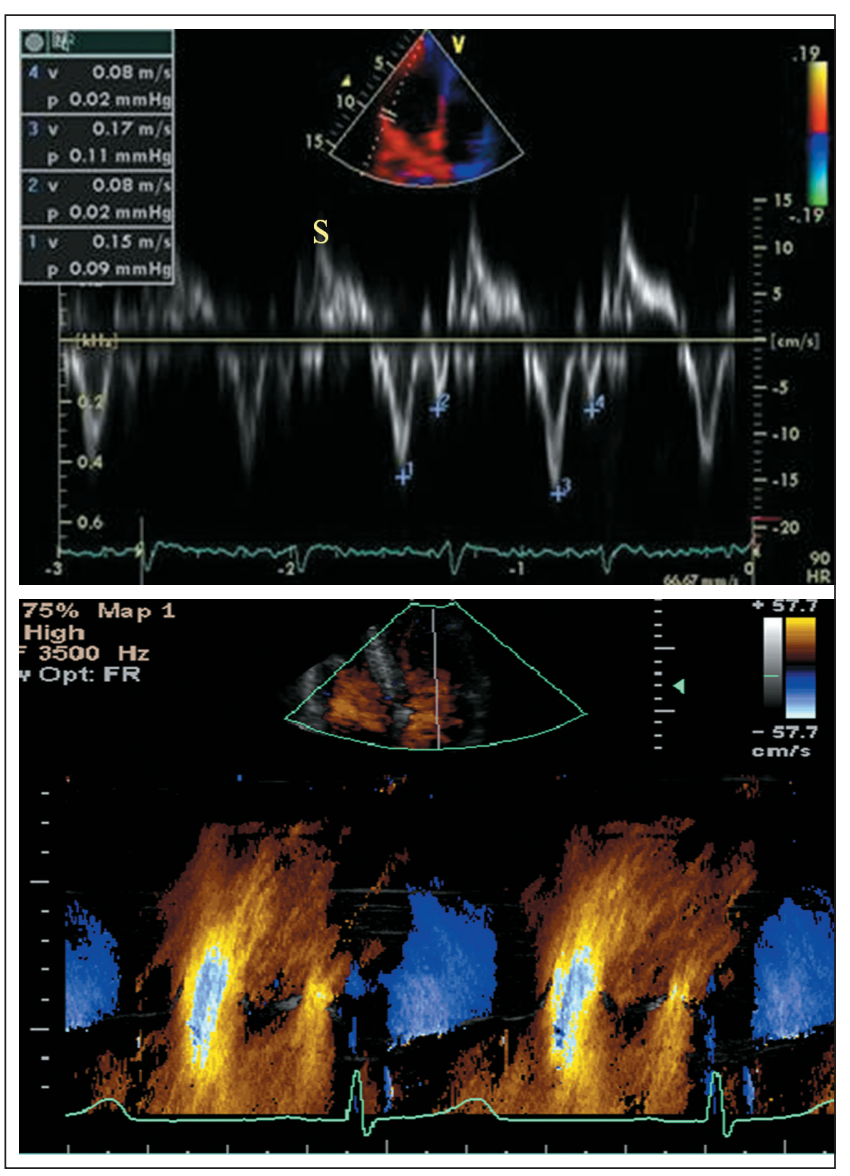

Figure 1

(A) Tissue Doppler of the lateral wall of the left ventricle (LV).

(B) Color M-mode showing mitral propagation flow.

$(\mathrm{Vp})$ higher than $55 \mathrm{~cm} / \mathrm{s}$ is considered normal for individuals younger than 30 years. ${ }^{25}$

\section{Left ventricular performance index (TEI index)}

The TEI index is the sum of the isovolumetric relaxation time and isovolumetric contraction time divided by the ventricular ejection time. This index evaluates LV systolic and diastolic functions.

\section{Calculating the left ventricular meridional stress}

The calculus of the LV circumferential stress uses the maximal systolic diameter of the LV, systolic width of the interventricular septum and posterior wall of the LV, and systolic blood pressure, as follows: ${ }^{26}$
SBP (systolic blood pressure) $x$ radius of the cavity $\div$ end systolic wall width

\section{Image storage and analysis}

Images were stored in the Echopac analysis system of the Vivid 7. All measurements were performed by two independent observers (level III) with inter- and intra-observer variations of $12.6 \%$ and $3.9 \%$.

\section{Parameters analyzed}

1 - Right measurements: left atrium (LA) and aorta (Ao); diastolic width of the septum (Sd), LV diastolic diameter (Dd), diastolic width of the posterior wall (Ppd), systolic width of the septum (Ss), LV systolic diameter (Ds), and systolic width of the posterior wall (Pps).

2 - Indirect measurements: diastolic volume $(\mathrm{Vd})$, systolic volume (Vs), LV mass (M), volume/mass ratio (V/M), systolic shortening of LV diameters (D\%), LV ejection fraction (EF), and mitral flow propagation velocity $(\mathrm{Vp})$.

The diastolic volume (Vd) and systolic volume (Vs) were calculated by elevating the diameters of the left ventricular cavity to the third potency $\left[\mathrm{Dd}^{3}\right.$ and $\left.\mathrm{Ds}^{3}\right]$.

The Devereux formula for measurement of the diameters and widths of the walls was used to calculate LV mass: ${ }^{27}$

$\mathrm{M}=1.04\left\{(\mathrm{Dd}+\mathrm{Sd}+\mathrm{Ppd})^{3}-\mathrm{Dd}^{3}\right\}-13.6$

3 - Measurements of flow velocity: rapid filling (E), atrial systole (A), velocity ratio (E/A), and systo-diastolic function (TEI INDEX).

Those measurements follow the Directives of the Canadian Consensus for echocardiographic measurement of diastolic dysfunction. ${ }^{28}$

4 - Lateral wall and septal regional indices: Contraction (S-lateral, S-septal), protodiastolic expansion (E'-lateral, E'septal), diastolic expansion (A'-lateral, A'-septal), velocity ratio (E'/A'-lateral, E'/A'-septal), and capillary wedge pressure (E/E'-lateral).

\section{Statistical analysis}

The Student $t$ test was used to analyze quantitative parameters after the observation of the minimal and maximal values and calculation of means and standard deviations (SD). The chi-square test or Fisher's exact test was used to compare velocities. The Spearman method was used for the correlation coefficient of the parameters. A level of significance of $5 \%$ was used in all tests. 


\section{RESULTS}

Mean age $(P=0.76)$, weight $(P=0.14)$, and body surface area $(\mathrm{SA})(\mathrm{P}=0.07)$ were similar in both groups, which are shown in Table 1. On the other hand, mean height was greater in the control group than in the group of SLE patients $(\mathrm{P}=0.048)$ (Table 1). Mean disease duration was $5.84 \pm 3.62$ years and SLEDAI $2.24 \pm 3.56$. All patients were being treated with prednisone (mean $5 \pm 2.50 \mathrm{mg} / \mathrm{d}$ ) and chloroquine diphosphate, $250 \mathrm{mg} / \mathrm{d}$.

Patients with systemic lupus erythematosus had a significant increase in heart rate $(\mathrm{P}=0.0001)$, systolic blood pressure $(\mathrm{P}=0.0001)$, and diastolic blood pressure $(\mathrm{P}=0.0001)$ that the control group (Table 1).

Echocardiography showed a significant increase of the left atrium and aorta of SLE patients, which can be seen in Table 1. Significant differences in the interventricular septum, both in systole and diastole, were also observed (Table 1). Besides, the posterior wall and volume of the LV were significantly greater in SLE patients, but only during diastole. On the other hand, LV diameter in systole and diastole was similar in both groups. The mass of the LV was significantly greater in SLE patients and, consequently, the LV volume/mass ratio was smaller in this group (Table 1).

Mean left ventricular systolic stress was significantly higher in the SLE group than in the control group (148.8 \pm 20.2 versus $141.0 \pm 15.6 \mathrm{mmHg} ; \mathrm{P}=0.035)$, as can be seen in Table 2 . Mean values of the remainder parameters of left ventricular function were similar in both groups (Table 2).

Similarly, mean proto- and telediastolic expansion velocity and ratio of diastolic velocities were similar in the SLE and control groups (Table 2). On the other hand, mean LV performance index was lower in the SLE group $(\mathrm{P}=0.0001)$ (Table 2).

Besides, mitral flow propagation velocity of the left ventricle was significantly lower in SLE than in the control group (47.6 \pm 8.4 versus $71.5 \pm 4.8 \mathrm{~cm} / \mathrm{s} ; \mathrm{P}=0.0001)$ (Table 3$)$. Mean ratio among protodiastolic velocities by color flow Doppler and $\mathrm{TD}$ at the level of the lateral wall of the mitral ring showed that the E/E' ratio was significantly greater in the SLE group than in the control group $(10.42 \pm 1.5$ versus $7.53 \pm 0.4 \mathrm{~cm} / \mathrm{s}$; $\mathrm{P}=0.0001$ ) (Table 3).

On the other hand, comparison of the mean proto- and telediastolic expansion velocities did not differ between both groups, which are shown in Table 4.

The correlation of disease duration with the echocardiographic measurements was significant only for the size of the LA $(\mathrm{r}=0.288 ; \mathrm{P}=0.0427)$, but not with the AO $(\mathrm{r}=0.105 ; \mathrm{P}=$ $0.467), \operatorname{SD}(r=0.217 ; \mathrm{P}=0.129), \operatorname{PPD}(\mathrm{r}=0.162 ; \mathrm{P}=0.258)$,
Table 1

Demographic characteristics and main echocardiographic (M-mode) parameters in SLE patients and control group

\begin{tabular}{|c|c|c|c|c|c|}
\hline \multirow[b]{2}{*}{ Parameter } & \multicolumn{2}{|c|}{ SLE $(n=50)$} & \multicolumn{2}{|c|}{ Control $(n=50)$} & \multirow[b]{2}{*}{$\mathbf{P}$} \\
\hline & Mean & Sd & Mean & Sd & \\
\hline \multicolumn{6}{|l|}{ Demographic } \\
\hline Age (years) & 27.86 & 5.53 & 28.16 & 4.30 & 0.76 \\
\hline Weight (Kg) & 57.73 & 9.31 & 60.50 & 9.40 & 0.14 \\
\hline Height (cm) & 159 & 6.96 & 161 & 5.70 & 0.048 \\
\hline $\mathrm{BS}\left(\mathrm{m}^{2}\right)$ & 1.58 & 0.14 & 1.63 & 0.12 & 0.07 \\
\hline HR (bpm) & 85.24 & 11.86 & 74.62 & 7.49 & 0.0001 \\
\hline $\mathrm{SBP}(\mathrm{mmHg})$ & 120.90 & 14.16 & 109.00 & 6.54 & 0.0001 \\
\hline $\mathrm{DBP}(\mathrm{mmHg})$ & 78.42 & 7.33 & 72.72 & 5.61 & 0.0001 \\
\hline \multicolumn{6}{|l|}{ Echocardiographic } \\
\hline $\mathrm{LA}(\mathrm{mm})$ & 33.30 & 3.48 & 30.64 & 2.90 & 0.001 \\
\hline $\mathrm{AO}(\mathrm{mm})$ & 30.20 & 2.46 & 28.78 & 2.20 & 0.0014 \\
\hline \multicolumn{6}{|c|}{ SEPTUM THICKNESS } \\
\hline SYSTOLIC (mm) & 9.14 & 1.24 & 8.04 & 0.69 & 0.0001 \\
\hline DIASTOLIC (mm) & 9.04 & 1.22 & 7.82 & 0.69 & 0.0001 \\
\hline \multicolumn{6}{|c|}{ POSTERIOR WALL LV } \\
\hline SYSTOLIC (mm) & 15.48 & 2.67 & 14.72 & 1.93 & 0.1073 \\
\hline DIASTOLIC (mm) & 8.96 & 1.10 & 7.76 & 0.65 & 0.0001 \\
\hline \multicolumn{6}{|l|}{ VOLUME LV } \\
\hline SYSTOLIC (mL) & 28.42 & 7.37 & 25.66 & 6.73 & 0.0537 \\
\hline DIASTOLIC (mL) & 113.82 & 24.27 & 103.82 & 24.57 & 0.0433 \\
\hline \multicolumn{6}{|l|}{ DIAMETER LV } \\
\hline SYSTOLIC (mm) & 30.06 & 2.50 & 29.28 & 2.48 & 0.1209 \\
\hline DIASTOLIC (mm) & 47.82 & 3.34 & 46.70 & 3.62 & 0.1118 \\
\hline \multicolumn{6}{|l|}{ LV } \\
\hline MASS (G) & 185.60 & 46.04 & 146.92 & 28.61 & 0.0001 \\
\hline $\mathrm{V} / \mathrm{M}(\mathrm{mL} / \mathrm{g})$ & 0.60 & 0.09 & 0.70 & 0.07 & $<0.001$ \\
\hline
\end{tabular}

SLE: systemic lupus erythematosus; BS: body surface; HR: heart rate; SBP: systolic blood pressure; DBP: diastolic blood pressure; LA: left atrium; AO: aorta; LV: left ventricle; V/M: volume/mass ratio; Kg: kilogram; cm: centimeter; m: meter; bpm: beats per minute; mmHg: millimeter of mercury; mm: millimeter; $\mathrm{mL}$ : milliliter; $\mathrm{mL} / \mathrm{g}$ : milliliter per gram.

$\mathrm{SS}(\mathrm{r}=0.226 ; \mathrm{P}=0.113), \mathrm{STRESS}(\mathrm{r}=0.092 ; \mathrm{P}=0.523), \mathrm{IM}$ $(\mathrm{r}=0.201 ; \mathrm{P}=0.160)$, and $\mathrm{V} / \mathrm{M}(\mathrm{r}=0.110 ; \mathrm{P}=0.446)$.

\section{DISCUSSION}

The women selected for this study were young and the mean age was similar in both groups (28 years), which was a consequence of adequate pairing. It is important to emphasize the exclusion of smoking and hypertension in our study that can influence echocardiographic measurements. ${ }^{29}$ 
Table 2

Systolic stress, systolic function, and left ventricular global and systo-diastolic performance indices of SLE patients and controls

\begin{tabular}{|c|c|c|c|c|c|}
\hline \multirow[b]{2}{*}{ Parameter } & \multicolumn{2}{|c|}{$\operatorname{SLE}(n=50)$} & \multicolumn{2}{|c|}{ Control $(n=50)$} & \multirow[b]{2}{*}{$\mathbf{P}$} \\
\hline & Mean & Sd & Mean & Sd & \\
\hline Systolic stress (mmhg) & 148.8 & 20.2 & 141.0 & 15.7 & 0.035 \\
\hline Ejection fraction (\%) & 74.68 & 2.47 & 75.42 & 2.35 & 0.1831 \\
\hline$d \%$ & 36.34 & 2.17 & 36.98 & 2.58 & 0.1292 \\
\hline e WAVE (m/s) & 0.81 & 0.13 & 0.82 & 0.13 & 0.8504 \\
\hline a WAVE (m/s) & 0.66 & 0.13 & 0.63 & 0.13 & 0.3194 \\
\hline e/a RATIO (m/s) & 1.25 & 0.24 & 1.31 & 0.21 & 0.2117 \\
\hline Lv PI (mmHg) & 0.34 & 0.03 & 0.45 & 0.08 & 0.0001 \\
\hline
\end{tabular}

SLE: systemic lupus erythematosus; D\%: percentage of left ventricular shortening; E WAVE: rapid filling; A Wave: atrial systole; E/A RATIO: relationship among regional diastolic velocities; LV PI: LV systo-diastolic performance index; mmHg: millimeter of mercury; $\mathrm{m} / \mathrm{s}$ : meter per second.

\section{Table 3}

Mitral flow propagation velocities and E/E' ratio of the wall of the mitral ring in SLE patients and controls

\begin{tabular}{lccccc}
\hline & \multicolumn{2}{c}{ SLE $(\mathbf{n}=\mathbf{5 0})$} & \multicolumn{2}{c}{ Control $(\mathbf{n}=\mathbf{5 0})$} & \multirow{2}{*}{ Parameter } \\
\cline { 2 - 5 } & Mean & Sd & Mean & Sd & P \\
\hline $\begin{array}{l}\text { Mitral flow } \\
\text { velocity }(\mathrm{cm} / \mathrm{s})\end{array}$ & 47.62 & 8.44 & 71.52 & 4.85 & 0.0001 \\
E/E' $(\mathrm{cm} / \mathrm{s})$ & 10.42 & 1.50 & 7.53 & 0.44 & 0.0001 \\
\hline
\end{tabular}

SLE: systemic lupus erythematosus; $E / E^{\prime}=$ indirect estimate of the left ventricular and pulmonary wedge pressures; $\mathrm{cm} / \mathrm{s}$ : centimeters per second.

\section{Table 4}

Regional indices of the lateral and septal wall of the left ventricle (LV) in SLE patients and controls

\begin{tabular}{|c|c|c|c|c|c|}
\hline \multirow[b]{2}{*}{ Parameter } & \multicolumn{2}{|c|}{ SLE $(n=50)$} & \multicolumn{2}{|c|}{ Control $(n=50)$} & \multirow[b]{2}{*}{$\mathbf{P}$} \\
\hline & Mean & Sd & Mean & Sd & \\
\hline \multicolumn{6}{|l|}{ Lateral } \\
\hline s wave $(\mathrm{cm} / \mathrm{s})$ & 7.50 & 2.41 & 10.31 & 2.95 & $<0.001$ \\
\hline e' wave $(\mathrm{cm} / \mathrm{s})$ & 11.06 & 3.46 & 15.64 & 2.89 & $<0.001$ \\
\hline a' wave $(\mathrm{cm} / \mathrm{s})$ & 7.76 & 3.18 & 7.76 & 2.53 & 0.9889 \\
\hline $\mathrm{e}^{\prime} / \mathrm{a}^{\prime}(\mathrm{cm} / \mathrm{s})$ & 1.75 & 1.04 & 2.21 & 0.72 & 0.0127 \\
\hline \multicolumn{6}{|l|}{ septum } \\
\hline s wave $(\mathrm{cm} / \mathrm{s})$ & 6.58 & 2.35 & 8.69 & 2.30 & $<0.001$ \\
\hline $\mathrm{e}^{\prime}$ wave $(\mathrm{cm} / \mathrm{s})$ & 8.50 & 2.69 & 12.2 & 2.77 & $<0.001$ \\
\hline a' wave $(\mathrm{cm} / \mathrm{s})$ & 7.64 & 1.92 & 8.11 & 2.53 & 0.2979 \\
\hline $\mathrm{e}^{\prime} / \mathrm{a}^{\prime}(\mathrm{cm} / \mathrm{s})$ & 1.18 & 0.45 & 1.60 & 0.46 & $<0.001$ \\
\hline
\end{tabular}

SLE: systemic lupus erythematosus; S WAVE: regional systolic contraction; E' WAVE: regional protodiastolic expansion; A' WAVE: regional telediastolic expansion; E'/A' RATIO: relationship among regional diastolic velocities; $\mathrm{cm} / \mathrm{s}$ : centimeters per second.
Although within normal limits, according to the American Society of Echocardiography ${ }^{22}$ and the Echocardiography Department of the Brazilian Society of Cardiology, ${ }^{21}$ in the present study, the diameters of the left atrium and aorta were higher in SLE patients. This finding cannot be explained by differences in height since significant increases in those parameters are not observed after the age of 15 years. ${ }^{29}$

On the other hand, the close relationship between left atrial dynamics and left ventricular filling pressures after opening of the mitral valve are well known. Normally, the atrial chamber contributes with the effective left ventricular ejection fraction and, in cases of diastolic dysfunction, an increase of the left atrium secondary to the elevation of LV filling pressures is observed. ${ }^{30}$ Thus, the increase in the left atrium observed in the present study must be reflecting an incipient diastolic dysfunction of the left ventricle. Indeed, the same findings were observed in SLE, in which increased atrial dimensions were observed, regardless of the evolutive phase of the disease.

Recently, a study on left atrial dynamics with TD has been gaining importance because it allows better analyzes of left atrial function, ${ }^{31}$ and it is also extremely important in the evaluation of diastolic dysfunction. Indeed, volume measurements are more reliable when evaluating an increase in the left atrium, and it is currently considered a predictive factor of the severity of the diastolic dysfunction. ${ }^{32-34}$ In the present study, the duration of the disease was directly related to the size of the left atrium, confirming that this measurement is an indirect sign of an incipient change in LV diastolic function. The same findings were observed in SLE patients with enlarged left atrium. ${ }^{9,10}$

The diameter of the aorta was also increased in SLE, probably due to an increase in blood pressure levels and left ventricular afterload. Indeed, in our study, blood pressure levels were higher in the SLE group, although still within normal limit according to the Fifth Report of the Joint National Committee on Detection, Evaluation, and Treatment of High Blood Pressu$\mathrm{re}^{35}$ and the III Brazilian Consensus on High Blood Pressure. ${ }^{36}$

Very few studies in the literature have measured isolate systolic myocardial thickness (systolic stress) in normal individuals. ${ }^{26,37}$ The increased systolic thickness seen in SLE patients may correspond to the increased myocardial effort to overcome greater systemic resistance, since it is directly proportional to the ventricular systolic pressure. The end-systolic dimensions of the myocardial fiber depend on the resistance imposed by the systemic circulation and left ventricular contractility. ${ }^{1}$ The increased diastolic thickness seen in SLE should correspond to the increase in end-diastolic volume, translating a difficul- 
ty to stretch the myocardial fiber in a ventricle with reduced compliance.

The increase in systolic and diastolic thickening seen in this disorder leads to an increase in rigidity and, consequently, in intraventricular pressure. ${ }^{38}$ In reality, the end-systolic volume was greater in SLE due to this increase in ventricular rigidity, disrupting ventricular filling. Besides, the end-diastolic volume was also increased in this disorder, indicating the involvement of the myocardium in SLE. All those factors predispose the worsening in diastolic function, leading to an increase in LV diastolic volume and filling pressures. Thus, this early alteration in ventricular volumes maybe the precursor of the process of ventricular dysfunction.

The ventricular mass was significantly higher in SLE because it incorporates the widths of the septum and posterior wall, which are important in face of an increase in after load and systolic blood pressure. Therefore, the volume/mass ratio was significantly lower in SLE, indicating the difficulty to adapt to the increased after load.

Since disease activity, as well as cardiopathies that might indicate myocardial involvement in SLE, were excluded, one would expect similar ventricular diameters and global systolic function in both SLE and control groups.

Conditions that lead to a chronic increase in pressure and/or volume predispose an increase in systolic stress and decrease ventricular performance. ${ }^{39}$ This increase in systolic stress in SLE shows a lack of ventricular adaptation in this disorder and can be helpful in the follow-up. On the other hand, the percentage of systolic shortening in the ventricular diameter, as well as ejection fraction, was similar in both groups, probably due to control of inflammatory activity at the time of evaluation. In fact, myocardial dysfunction during the course of this disorder has been reported in 5 to $10 \%$ of the cases,,$^{10,12,13,17,40,41}$ which can be exacerbated by the inflammatory process associated with SLE. ${ }^{13,42}$ This hypothesis is supported by the report of global systolic dysfunction of the left ventricle in young patients with less than 2 years of SLE whose myocardial dysfunction improved after treatment with corticosteroids. ${ }^{18}$

Mitral flow propagation velocity is another method incorporated in the assessment of diastolic function, and it allows the assessment of left ventricular relaxation velocity, therefore providing reliable information on the temporal and spatial distribution of the process of ventricular relaxation. ${ }^{43}$ In the present study, we observed a reduction in this velocity, due to the difficulty to relax basal portions of the left ventricle, in patients with SLE.

Conventional mitral Doppler flowmetry has a biphasic wave in which the $\mathrm{E}$ wave corresponds to the phase of rapid ventricular filling and the A wave corresponds to the atrial contraction. Abnormalities in early (E wave) and late (A wave) diastolic velocities were not observed in SLE patients probably because they were young and the disease was stable and, therefore, the left ventricle can use an elasticity reserve. In fact, prior assessment of 20 SLE patients (mean age of 38 years) identified changes in diastolic dysfunction, characterized by a reduction in $\mathrm{E}$ wave and increase in A wave, which were attributed to the degree of inflammation. ${ }^{17}$ Later, it was observed that age was the only factor related with changes in $\mathrm{E}$ and $\mathrm{A}$ waves in SLE. ${ }^{42}$ In reality, the behavior of the $\mathrm{E}$ and $\mathrm{A}$ waves depend on the pressure gradient between the left atrium and ventricle, being influenced by preload, age, and heart rate, ${ }^{28}$ which might have hindered detection of diastolic dysfunction by this method in the present study. Left ventricular performance index (TEI index), based solely on Doppler, provides an estimate of the global ventricular behavior, and it is not influenced by blood pressure or heart rate. ${ }^{44}$ In the present study, the TEI index of lupus patients was within normal limits because the diastolic dysfunction observed was regional.

On the other hand, the regional ventricular diastolic function determined by Tissue Doppler in this study demonstrated regional involvement in SLE, more pronounced in the basal portion of the interventricular septum. In other cardiopathies, this change in diastolic function precedes changes in systolic function, and it is detected in isolated segments of the left ventricle, but it is more frequent in basal portions..$^{45}$ Using maximal regional velocities, which defines speeds of $17.3 \pm 3.0$ and $13.5 \pm 2.2 \mathrm{~cm} / \mathrm{s}$ for the lateral and septal walls of the mitral ring, respectively, as reference of normalcy ${ }^{46}$, we observed a pattern of alteration in left ventricular regional relaxation and in the phase of rapid filling in SLE patients, represented by a reduction in the maximal velocity of the E' wave. Besides, the E'/A' ratio was smaller in SLE patients. Detection of regional diastolic dysfunction in SLE might represent an early change in left ventricular relaxation and it would precede global diastolic dysfunction.

The relationship between maximal left atrial protodiastolic emptying velocities measured by conventional Doppler flowmetry (E wave) and that of TD (E' wave) evaluated in the present study was above 10 in SLE, indicating an increase in filling pressures that would cause retrograde elevation of the left atrial pressure and pulmonary wedge pressure. This increase in ventricular filling pressures would explain the left atrial dilation, preventing it to spread to the pulmonary circulation. ${ }^{47}$ The E/E' relationship seems to be extremely useful in detecting dysfunction in SLE patients. ${ }^{40}$ In fact, an $\mathrm{E} / \mathrm{E}$ ' ratio $>10$ indicates the presence of a pulmonary wedge 
pressure of about $15 \mathrm{mmHg},{ }^{48}$ being a predictor of elevated ventricular filling pressure. ${ }^{23}$ Therefore, this relationship could be an early marker of diastolic dysfunction of any etiology, including in SLE patients.

The present study demonstrated the importance of the early detection of this condition in SLE patients, since disruption of LV regional diastolic function can be demonstrated by Tissue Doppler and global left ventricular diastolic function can be identified by analyzing mitral flow propagation velocity.

\section{REFERÊNCIAS}

\section{REFERENCES}

1. Otto CM. The practice of clinical echocardiography. Second edition, 2002.

2. Kitabatake A, Inoue M, Asao M, Tanouchi J, Masuyama T, Abe H et al. Transmitral blood flow reflecting diastolic behavior of the left ventricle in health and disease: a study by pulsed Doppler technique. Jpn Circ J 1982; 46(1):92-102.

3. Badano LP, Albanese MC, De Biaggio P, Rozbowsky P, Miani D, Fresco C et al. Prevalence, clinical characteristics, quality of life, and prognosis of patients with congestive heart failure and isolated left ventricular diastolic dysfunction. J Am Soc Echocardiogr 2004; 17(3):253-61.

4. Nishimura RA, Abel MD, Hatle LK, Tajik AJ. Assessment of diastolic function of the heart: background and current applications of Doppler echocardiography. Part II. Clinical studies. Mayo Clin Proc 1989; 64(2):181-204.

5. Waggoner AD, Bierig SM. Tissue Doppler imaging: a useful echocardiographic method for the cardiac sonographer to assess systolic and diastolic ventricular function. J Am Soc Echocardiogr 2001; 14(12):1143-52.

6. Garcia MJ, Thomas JD, Klein AL. New Doppler echocardiographic applications for the study of diastolic function. J Am Coll Cardiol 1998; 32(4):865-75.

7. Voon WC, Su HM, Yen HW, Lin TH, Huang CH, Chu CS et al. Propagation velocity of mitral late flow toward the apex in healthy participants. J Am Soc Echocardiogr 2004; 17(8):851-4.

8. Morelli S, Bernardo ML, Viganego F, Sgreccia A, De Marzio P, Conti $\mathrm{F}$ et al. Left-sided heart valve abnormalities and risk of ischemic cerebrovascular accidents in patients with systemic lupus erythematosus. Lupus 2003; 12(11):805-12.

9. Leung WH, Wong KL, Lau CP, Wong CK, Cheng CH, Tai YT. Doppler echocardiographic evaluation of left ventricular diastolic function in patients with systemic lupus erythematosus. Am Heart J 1990; 120(1):82-7.

10. Leung WH, Wong KL, Lau CP, Wong CK, Cheng CH. Cardiac abnormalities in systemic lupus erythematosus: a prospective M-mode, cross-sectional and Doppler echocardiographic study. Int J Cardiol 1990; 27(3):367-75.

11. Leung WH, Wong KL, Lau CP, Wong CK, Liu HW. Association between antiphospholipid antibodies and cardiac abnormalities in patients with systemic lupus erythematosus. Am J Med 1990; 89(4):411-9.
12. Sasson Z, Rasooly Y, Chow CW, Marshall S, Urowitz MB. Impairment of left ventricular diastolic function in systemic lupus erythematosus. Am J Cardiol 1992; 69(19):1629-34.

13. Kalke S, Balakrishanan C, Mangat G, Mittal G, Kumar N, Joshi VR. Echocardiography in systemic lupus erythematosus. Lupus 1998; 7(8):540-4.

14. Roldan CA, Shively BK, Crawford MH. An echocardiographic study of valvular heart disease associated with systemic lupus erythematosus. N Engl J Med 1996; 335(19):1424-30.

15. Leszczyński P, Straburzyńska-Migaj E, Korczowska I, Łacki JK, Mackiewicz S. Cardiac valvular disease in patients with systemic lupus erythematosus. Relationship with anticardiolipin antibodies. Clin Rheumatol 2003; 22(6):405-8.

16. Falcão CA, Alves IC, Chahade WH, Duarte AL, Lucena-Silva N. Echocardiographic abnormalities and antiphospholipid antibodies in patients with systemic lupus erythematosus. Arq Bras Cardiol 2002; 79(3):285-91

17. Paradiso M, Gabrielli F, Masala C, Coppotelli L, Di Franco M, Paoletti V et al. Evaluation of myocardial involvement in systemic lupus erythematosus by signal-averaged electrocardiography and echocardiography. Acta Cardiol 2001; 56(6):381-6.

18. Gottenberg JE, Roux S, Assayag P, Clerc D, Mariette X. Specific cardiomyopathy in lupus patients: report of three cases. Joint Bone Spine 2004; 71(1):66-9.

19. Tan EM, Cohen AS, Fries JF, Masi AT, McShane DJ, Rothfield NF et al. The 1982 revised criteria for the classification of systemic lupus erythematosus. Arthritis Rheum 1982; 25(11):1271-7.

20. Bombardier C, Gladman DD, Urowitz MB, Caron D, Chang CH. Derivation of the SLEDAI. A disease activity index for lupus patients. The Committee on Prognosis Studies in SLE. Arthritis Rheum 1992; 35(6):630-40

21. Silva CE, Tasca R, Weitzel LH, Moisés VA, Ferreira LD, Tavares GM et al. Brazilian Society of Cardiology. Standardization of equipment and techniques for conducting echocardiographic examinations. Arq Bras Cardiol 2004; 82(Suppl 2):1-10.

22. Lang RM, Bierig M, Devereux RB, Flachskampf FA, Foster E, Pellikka PA et al. Chamber Quantification Writing Group; American Society of Echocardiography's Guidelines and Standards Committee; European Association of Echocardiography. Recommendations for chamber quantification: a report from the American Society of Echocardiography's Guidelines and Standards Committee and the Chamber Quantification Writing Group, developed in conjunction with the European Association of Echocardiography, a branch of the European Society of Cardiology. J Am Soc Echocardiogr 2005; 18(12):1440-63.

23. Ommen SR, Nishimura RA, Appleton CP, Miller FA, Oh JK, Redfield MM et al. Clinical utility of Doppler echocardiography and tissue Doppler imaging in the estimation of left ventricular filling pressures: A comparative simultaneous Doppler-catheterization study. Circulation 2000; 102(15):1788-94.

24. Rivas-Gotz C, Manolios M, Thohan V, Nagueh SF. Impact of left ventricular ejection fraction on estimation of left ventricular filling pressures using tissue Doppler and flow propagation velocity. Am J Cardiol 2003; 91(6):780-4.

25. Khouri SJ, Maly GT, Suh DD, Walsh TE. A practical approach to the echocardiographic evaluation of diastolic function. J Am Soc Echocardiogr 2004; 17(3):290-7. 
26. Quinones MA, Mokotoff DM, Nouri S, Winters WL Jr, Miller RR. Noninvasive quantification of left ventricular wall stress. Validation of method and application to assessment of chronic pressure overload. Am J Cardiol 1980; 45(4):782-90.

27. Devereux RB. Left ventricular geometry, pathophysiology and prognosis. J Am Coll Cardiol 1995; 25(4):885-7.

28. Rakowski H, Appleton C, Chan KL, Dumesnil JG, Honos G, Jue J et al. Canadian consensus recommendations for the measurement and reporting of diastolic dysfunction by echocardiography: from the Investigators of Consensus on Diastolic Dysfunction by Echocardiography. J Am Soc Echocardiogr 1996; 9(5):736-60.

29. Nidorf SM, Picard MH, Triulzi MO, Thomas JD, Newell J, King ME et al. New perspectives in the assessment of cardiac chamber dimensions during development and adulthood. J Am Coll Cardiol 1992; 19(5):983-8.

30. Zile MR, Baicu CF, Gaasch WH. Diastolic heart failure-abnormalities in active relaxation and passive stiffness of the left ventricle. N Engl J Med 2004; 350(19):1953-9.

31. Paredes MP, Gonzalvez M, Almagro FG, Cubero T. Evaluacion de las velocidades de pared de la aurícula izquierda mediante Doppler pulsado tisular. Uma nueva aproximación al estúdio de la función auricular. Rev Espanhola Cardiol 2004: 57(11):1059-65.

32. Rossi A, Cicoira M, Zanolla L, Sandrini R, Golia G, Zardini P et al. Determinants and prognostic value of left atrial volume in patients with dilated cardiomyopathy. J Am Coll Cardiol 2002; 40(8):1425.

33. Pritchett AM, Jacobsen SJ, Mahoney DW, Rodeheffer RJ, Bailey KR, Redfield MM. Left atrial volume as an index of left atrial size: a population-based study. J Am Coll Cardiol 2003; 41(6):1036-43.

34. Tirrito SJ, Augustine DR, Kerut EK. How to measure left atrial volume. Echocardiography 2004; 21(6):569-71.

35. Chobanian AV, Bakris GL, Black HR, Cushman WC, Green LA, Izzo JL Jr et al. National Heart, Lung, and Blood Institute Joint National Committee on Prevention, Detection, Evaluation, and Treatment of High Blood Pressure; National High Blood Pressure Education Program Coordinating Committee. The Seventh Report of the Joint National Committee on Prevention, Detection, Evaluation, and Treatment of High Blood Pressure: the JNC 7 report. JAMA 2003; 289(19):2560-72.

36. Sociedade Brasileira de Cardiologia-SBC; Sociedade Brasileira de Hipertensão-SBH; Sociedade Brasileira de Nefrologia-SBN. [V Brazilian Guidelines in Arterial Hypertension]. Arq Bras Cardiol 2007; 89(3):e24-79.
37. Marsh JD, Green LH, Wynne J, Cohn PF, Grossman W. Left ventricular end-systolic pressure-dimension and stress-length relations in normal human subjects. Am J Cardiol 1979; 44(7):1311-7.

38. Zile MR, Brutsaert DL. New concepts in diastolic dysfunction and diastolic heart failure: Part I: diagnosis, prognosis, and measurements of diastolic function. Circulation 2002; 105(11):1387-93.

39. Ganau A, Devereux RB, Roman MJ, de Simone G, Pickering TG, Saba PS et al. Patterns of left ventricular hypertrophy and geometric remodeling in essential hypertension. J Am Coll Cardiol 1992; 19(7):1550-8.

40. Lee SW, Park MC, Park YB, Lee SK. E/E' ratio is more sensitive than E/A ratio for detection of left ventricular diastolic dysfunction in systemic lupus erythematosus. Lupus 2008; 17(3):195-201.

41. Fujimoto S, Kagoshima T, Nakajima T, Dohi K. Doppler echocardiographic assessment of left ventricular diastolic function in patients with systemic lupus erythematosus. Cardiology 1994; 85(3-4):267-72.

42. Wislowska M, Dereń D, Kochmański M, Sypuła S, Rozbicka J. Systolic and diastolic heart function in SLE patients. Rheumatol Int 2009; 25 [Epub ahead of print].

43. Garcia MJ, Smedira NG, Greenberg NL, Main M, Firstenberg MS, Odabashian J et al. Color M-mode Doppler flow propagation velocity is a preload insensitive index of left ventricular relaxation: animal and human validation. J Am Coll Cardiol 2000; 35(1):201-8.

44. Spencer KT, Kirkpatrick JN, Mor-Avi V, Decara JM, Lang RM. Age dependency of the Tei index of myocardial performance. J Am Soc Echocardiogr 2004; 17(4):350-2.

45. Nagueh SF, Sun H, Kopelen HA, Middleton KJ, Khoury DS. Hemodynamic determinants of the mitral annulus diastolic velocities by tissue Doppler. J Am Coll Cardiol 2001; 37(1):278-85.

46. De Boeck BW, Cramer MJ, Oh JK, van der Aa RP, Jaarsma W. Spectral pulsed tissue Doppler imaging in diastole: a tool to increase our insight in and assessment of diastolic relaxation of the left ventricle. Am Heart J 2003; 146(3):411-9.

47. Garcia MJ, Ares MA, Asher C, Rodriguez L, Vandervoort P, Thomas JD. An index of early left ventricular filling that combined with pulsed Doppler peak E velocity may estimate capillary wedge pressure. J Am Coll Cardiol 1997; 29(2):448-54.

48. Nagueh SF, Middleton KJ, Kopelen HA, Zoghbi WA, Quiñones MA. Doppler tissue imaging: a noninvasive technique for evaluation of left ventricular relaxation and estimation of filling pressures. J Am Coll Cardiol 1997; 30(6):1527-33. 